\title{
Correction to: Utility of functional lumen imaging probe in esophageal measurements and dilations: a single pediatric center experience
}

\author{
Kenneth $\mathrm{Ng}^{1}{ }^{1}$. Douglas Mogul ${ }^{1} \cdot$ John Hollier $^{3} \cdot$ Mouen A. Khashab $^{2}$
}

Published online: 25 June 2019

(c) Springer Science+Business Media, LLC, part of Springer Nature 2019

\section{Correction to: Surgical Endoscopy} https://doi.org/10.1007/s00464-019-06898-5

This article has been corrected to include the middle initial of senior author Mouen A. Khashab.

Publisher's Note Springer Nature remains neutral with regard to jurisdictional claims in published maps and institutional affiliations.

The original article can be found online at https://doi.org/10.1007/ s00464-019-06898-5.

Kenneth $\mathrm{Ng}$

kng13@jhmi.edu

1 Department of Pediatrics, Johns Hopkins University School of Medicine, Baltimore, MD, USA

2 Department of Medicine, Johns Hopkins University School of Medicine, Baltimore, MD, USA

3 Department of Pediatrics, Baylor College of Medicine, Houston, TX, USA 